\title{
Protein Diet and Estimated Glomerular Filtration Rate
}

\author{
Supatra Lohsiriwat \\ Department of Physiology, Faculty of Medicine Siriraj Hospital, Mahidol University, Bangkok, Thailand \\ Email: supatra.1oh@mahidol.ac.th
}

Received April 3, 2013; revised May 7, 2013; accepted May 22, 2013

Copyright (C) 2013 Supatra Lohsiriwat. This is an open access article distributed under the Creative Commons Attribution License, which permits unrestricted use, distribution, and reproduction in any medium, provided the original work is properly cited.

\begin{abstract}
Chronic kidney disease (CKD) is a common health problem worldwide. CKD staging or classification, together with patients' prognosis and treatment plan depend on the patients' kidney function which is assessed by measurement of glomerular filtration rate (GFR). Estimated GFR can be obtained using serum or plasma creatinine as a main variable in equations or formulae such as Cockcroft-Gault equation, MDRD equation (Modification of Diet in Renal Disease), the Schwartz and Counahan-Barratt formulae. These equations, though widely accepted, still have to be adjusted or validated among different groups of patients according to the variation in some factors such as race, diet, and genetic heterogenicity. Diet, especially the high protein load, can affect GFR representing the renal functional reserve. A high protein diet can cause an increase in GFR that lasts for many hours. Long-term consumption of vegetarian diet which is low in protein and contains only protein from plant sources can cause a low baseline GFR while the renal functional reserve is still preserved. This paper aims to remind of the role of protein diet effect on GFR measurement especially when assessing the renal function in vegetarians or individuals on long-term low-protein intake.
\end{abstract}

Keywords: Protein Diet; Glomerular Filtration Rate; eGFR; Vegetarian

\section{Introduction}

Chronic kidney disease (CKD) is becoming an increasing health problem in many countries, its prevalence and staging were studied and reported from all over the globe including United States [1], Australia [2], European countries [3], the Republic of China [4], and Japan [5]. In Thailand, the National Health Examination Survey 2004 found that the prevalence of CKD (compiling only those of stage 3, 4 and 5) in Thai adults was $8.45 \%$ [6].

These reports show that CKD is becoming a more serious problem worldwide as the patients with end stage renal disease (ESRD) need dialysis and/or transplantation which need complicate health care and also a high cost of health service. CKD stages were most often classified based on Kidney Disease Outcome Quality Initiatives (K/DOQI) which classified CKD patients into 5 stages according to their glomerular filtration rate (GFR) [7]. So the measurement of GFR should be reliable and accurate.

Intake of cooked meat has a significant effect on serum creatinine concentration and GFR. Misclassification of CKD is possible if measurements are made after high protein diet [8], and in individuals with exceptional dietary intake such as vegetarian [9].

\section{GFR Measurement: Clearance Technique}

GFR provides the best index of overall kidney function especially glomerular function. GFR is not measured directly but can be assessed by clearance technique using creatinine, inulin, radionuclide-labeled markers, radiocontrast markers or other substances that are freely filtered but not transported in the renal tubules. Clearance (C) of a substance is the rate at which an indicator substance is removed from plasma per unit concentration, specifying a volume from which all of the substance is removed per unit time. Clearance can be calculated from the formula $\mathrm{C}=\mathrm{UV} / \mathrm{P}$, where $\mathrm{C}$ is clearance in $\mathrm{ml} / \mathrm{min}, \mathrm{U}$ means the urine concentration of the substance in $\mathrm{mg} / \mathrm{mL}$, $\mathrm{V}$ means the urine volume in one minute and $\mathrm{P}$ means plasma concentration of the substance in $\mathrm{mg} / \mathrm{mL}[10,11]$.

\section{Estimated GFR (eGFR)}

Clearance method needs accurate urine collection which is not easily accomplished, time consuming and can be cumbersome leading to inadequate compliance and unreliability. In 1976 Cockcroft and Gault proposed the prediction of creatinine clearance from serum creatinine $\left(\mathrm{S}_{\mathrm{cr}}\right)$ 
[12]. The principle has been accepted, modified, and called estimated GFR.

Cockcroft-Gault equation predicts clearance of creatinine $(\mathrm{Ccr})$ as $\mathrm{Ccr}=(140-$ age $) \times($ weight $) /(72 \times \mathrm{Scr})$ (multiply by 0.85 if female).

Other equations to estimate GFR from serum creatinine have come out and been widely used as well. Levey et al. [13] in 1999 presented a new prediction equation called the MDRD equation (Modification of Diet in Renal Disease) claimed to be more accurate especially in the black.

$\mathrm{eGFR}=170 \times\left[\mathrm{S}_{\mathrm{cr}}(\mathrm{mg} / \mathrm{dL})\right]^{-0.999} \times[\mathrm{age}]^{-0.176} \times[0.762$ if patient is female] $\times$ [1.18 if patient is black].

Among children, the Schwartz [14] and Counahan-Barratt [15] formulae provide clinical useful estimates of GFR.

Manjunath et al. in 2001 stated that measurement of creatinine clearance using timed (e.g., 24-hour) urine collections does not improve the estimate of GFR over that provided by prediction equations. Anyhow, they indicated that a 24-hour urine sample provides useful information for GFR estimation in individuals with exceptional dietary intake (vegetarian diet, use of creatine supplements) or muscle mass (amputation, malnutrition, muscle wasting) [16].

\section{Variation of Serum Creatinine}

Creatinine has a molecular weight of 113 D. It is a break down product of creatine and phosphocreatine in muscle, and is usually produced at a rather constant rate in the body. Creatinine generation is proportional to muscle mass. The liver plays important role in formation of creatinine through methylation of guanidine aminoacetic acid [17].

Creatinine is freely filtered by the renal glomeruli. There is no renal tubular reabsorption of the substance, while approximately $3 \%$ of creatinine in the urine is secreted from the renal tubules. With a decrease in GFR, blood concentration of creatinine rises, presenting a reciprocal relationship between GFR and serum creatinine concentration.

In CKD patients with reduced glomerular and nephron function, serum creatinine rises and renal tubular secretion of creatinine is in relatively higher proportion.

Elevated level of serum creatinine usually indicates reduced GFR, but normal level does not exclude possibility of reduced GFR especially when renal damage is not immense. Renal clearance representing GFR is a more accurate method to measure kidney function.

Serum creatinine level can be affected by numerous factors. It is slightly increased just after ingestion of high meat diet, vigorous exercise, or due to some drugs that block tubular secretion of creatinine especially in CKD patients who already have high concentration of creatinine in the blood. Serum creatinine level is lower in individuals with muscle wasting, malnutrition, dietary protein restriction, and advanced liver disease. So in CKD patients with severe malnutrition and severe muscle wasting, serum creatinine might not be as high as in those with more muscle mass though their kidney functions are in the same level.

\section{Protein Diet and GFR, Renal Functional Reserve}

Intake of cooked meat has a significant effect on serum creatinine concentration and GFR $[18,19]$. Proteins of different sources, for example animal protein vs vegetable protein, do not affect GFR at the same magnitude $[20,21]$,

The capacity of the kidney to increase its renal blood flow and GFR after a dietary protein load is called renal functional reserve [22]. The increase in GFR after high protein diet can be due both to an increase in the serum creatinine concentration and the known postprandial increase of true GFR $[8,22]$. Healthy vegetarians are known to have a statistically reduced baseline GFR [18] but the ability to increase the GFR after high protein diet is still maintained [23], unlike in patients with a reduced number of nephrons whose renal functional reserve may be diminished or absent [22].

Protein diet from animal source produced more increment in postprandial GFR compared to that from vegetable source [21]. Kontessis et al. in 1995 reported that, after a high protein diet of animal source, plasma concentrations of valine, lysine, and IGF-I were higher than after a vegetable protein diet, while the plasma levels of growth hormone and glucagon did not differ significantly. The plasma valine was strongly correlated to the GFR [20].

\section{The Classification of Chronic Kidney Disease in Vegetarian}

Since the classification of chronic kidney disease is based on baseline GFR [7], and strict and long-term healthy vegetarians are known to have a statistically reduced baseline GFR [18], therefore physicians need to bear this in mind when dealing with diagnosis and classification of chronic kidney disease in vegetarians. Barai et al. reported that basal GFR in 109 healthy Indian subjects consuming vegetarian diet for 10 days was $82.4 \pm 12.7$ $\mathrm{mL} / \mathrm{min} / 1.73$ sq.m. which was significantly lower than the normal value of $120-130 \mathrm{~mL} / \mathrm{min} / 1.73$ sq.m. in western population [24]. They suggested that the conventional cutoff value of $60 \mathrm{~mL} / \mathrm{min} / 1.73 \mathrm{sq} . \mathrm{m}$. for defining chronic kidney disease might not be appropriate in India. Preiss et al. in 2007 concluded in their report that mis- 
classification of chronic kidney disease is possible if measurement of serum creatinine and GFR estimation are made after meat-containing meals [8]. Wiseman et al. measured GFR (as 51Cr-EDTA clearance) in vegans and lactovegetarians in comparison to omnivorous control subjects matched for age [25]. They found lower GFR in vegans and lactovegetarians but higher mean urinary albumin excretion rate in the omnivores.

In Thailand, it is our Thai tradition to consume rice meals with more carbohydrate and local vegetables, with less meat than the western style, especially in the rural area. The effect of meat on baseline serum creatinine and GFR estimation may play some minor part when dealing with diagnosis and classification of chronic kidney disease.

\section{Conclusion}

Vegetarians and individuals consuming long-term lowprotein diet exhibit low baseline GFR though their renal functional reserve is still preserved. To assess renal function or survey of the prevalence of CKD using single measurement of baseline GFR, these low protein consumers may be mistaken as patients with early stages of CKD.

\section{REFERENCES}

[1] J. Coresh, B. Astor, T. Greene, G. Eknoyan and A. Levey, "Prevalence of Chronic Kidney Disease and Decreased Kidney Function in the Adult US Population: Third National Health and Nutrition Examination Survey," American Journal of Kidney Diseases, Vol. 41, No. 1, 2003, pp. 1-12. doi:10.1053/ajkd.2003.50007

[2] R. C. Atkins, K. R. Polkinghorne, E. M. Briganti, J. E. Shaw, P. Z. Zimmet and S. J. Chadban, "Prevalence of Albuminuria in Australia. The Ausdiab Kidney Study," Kidney International, Vol. 66, 2004, pp. S22-S24. doi:10.1111/j.1523-1755.2004.09206.x

[3] B. Rutkowski and E. Krol, "Epidemiology of Chronic Kidney Disease in Central and Eastern Europe," Blood Purification, Vol. 26, 2008, pp. 381-385. doi: $10.1159 / 000137275$

[4] C. P. Wen, T. Y. Cheng, M. K. Tsai, et al., "All-Cause Mortality Attributable to Chronic Kidney Disease: A Prospective Cohort Study Based on 462,293 Adults in Taiwan," Lancet, Vol. 371, No. 9631, 2008, pp. 2173-2182. doi:10.1016/S0140-6736(08)60952-6

[5] T. Konta, Z. Hao, H. Abiko, et al., "Prevalence and Risk Factor Analysis of Microalbuminuria in Japanese General Population: The Takahata Study," Kidney International, Vol. 70, 2006, pp. 751-756. doi:10.1038/sj.ki.5001504

[6] L. Ong-Ajyooth, K. Vareesangthip, P. Khonputsa and W. Aekplakorn, "Prevalence of Chronic Kidney Disease in Thai Adults: A National Health Survey," BMC Nephrology, Vol. 10, 2009, p. 35. doi:10.1186/1471-2369-10-35

[7] "National Kidney Foundation. K/DOQI Clinical Practice Guidelines for Chronic Kidney Disease: Evaluation, Classification, and Stratification," American Journal of Kidney Diseases, Vol. 39, No. 5, 2002, pp. S1-266. doi:10.1016/S0272-6386(02)70054-1

[8] D. J. Preiss, I. M. Godber, E. J. Lamb, R. N. Dalton and I. R. Gunn, "The Influence of a Cooked-Meat Meal on Estimated Glomerular Filtration Rate," Annals of Clinical Biochemistry, Vol. 44, No. 1, 2007, pp. 35-42. doi:10.1258/000456307779595995

[9] G. Manjunath, M. J. Sarnak and A. S. Levey, "Estimating the Glomerular Filtration Rate. Dos and Don'ts for Assessing Kidney Function," Postgraduate Medicine, Vol. 110, No. 6, 2001, pp. 55-62.

[10] P. B. Rehberg, "Studies on Kidney Function I. The Rate of Filtration and Reabsorption in the Human Kidney," Biochemical Journal, Vol. 20, 1926, p. 447.

[11] J. M. Hayman Jr., J. A. Halsted and L. E. Seyler, "A Comparison of the Creatinine and Urea Clearance Tests of Kidney Function," JCI, Vol. 12, No. 5, 1933, pp. 861875. doi:10.1172/JCI100545

[12] D. W. Cockcroft and M. H. Gault, "Prediction of Creatinine Clearance from Serum Creatinine," Nephron, Vol. 16, No. 1, 1976, pp. 31-41. doi:10.1159/000180580

[13] A. S. Levey, J. P. Bosch, J. B. Lewis, T. Greene, N. Rogers and D. Roth, "A More Accurate Method to Estimate Glomerular Filtration Rate from Serum Creatinine: A New Prediction Equation. Modification of Diet in Renal Disease Study Group," Annals of Internal Medicine, Vol. 130, No. 6, 1999, pp. 461-470. doi:10.7326/0003-4819-130-6-199903160-00002

[14] G. L. Schwartz and B. Gauthier, "A Simple Estimate of Glomerular Filtration Rate in Adolescent Boys," The Journal of Pediatrics, Vol. 106, No. 3, 1985, pp. 522-526. doi:10.1016/S0022-3476(85)80697-1

[15] R. Counahan, C. Chantler, S. Ghazali, B. Kirkwood, F. Rose and T. M. Barrett, "Estimation of Glomerular Filtration Rate from Plasma Creatinine Concentration in Children," Archives of Disease in Childhood, Vol. 51, No. 11, 1976, pp. 875-878. doi:10.1136/adc.51.11.875

[16] G. Manjunath, M. J. Sarnak and A. S. Levey, "Estimating the Glomerular Filtration Rate. Dos and Don'ts for Assessing Kidney Function," Postgraduate Medicine, Vol. 110, No. 6, 2001, pp. 55-62.

[17] M. H. Rosner and K. Bolton, "Core Curriculum in Nephrology. Renal Function Test," American Journal of Kidney Diseases, Vol. 47, No. 1, 2006, pp. 174-183. doi:10.1053/j.ajkd.2005.08.038

[18] R. Hirschberg, H. Rottka, D. von Herrath, A. Pauls and K. Schaefer, "Effect of an Acute Protein Load on the Creatinine Clearance in Healthy Vegetarian," Klinische Wochenschrift, Vol. 63, No. 5, 1985, pp. 217-220. doi:10.1007/BF01731172

[19] S. Lohsiriwat and M. Sriponyaskul, "Effect of High-Protein Diet on the Glomerular Filtration Rate in the Adult and the Elderly," Siriraj Medical Journal, Vol. 51, 1999, pp. 21-26. 
[20] P. A. Kontessis, I. Bossinakou, L. Sarika, E. Iliopoulou, A. Papantiniou, R. Trevisan, D. Roussi, K. Stipsanelli, S. Grigorakis and A. Souvatzoglou, "Renal, Metabolic, and Hormonal Responses to Proteins of Different Origin in Normotensive, Nonproteinuric Type I Diabetic Patients," Diabetic Care, Vol. 18, No. 9, 1995, p. 1233. doi:10.2337/diacare.18.9.1233

[21] S. Lohsiriwat and S. Thophol, "Effects of Vegetable and Animal Protein Meals on Glomerular Filtration Rate," The Nephrology Society of Thailand, Vol. 6, 2000, pp. 217-223.

[22] J. P. Bosch, A. Saccaggi, A. Lauer, C. Ronco, M. Belledonne and S. Glabman, "Renal Functional Reserve in Humans. Effect of Protein Intake on Glomerular Filtration Rate," The American Journal of Medicine, Vol. 75, No. 6, 1983, pp. 943-950. doi:10.1016/0002-9343(83)90873-2
[23] S. Lohsiriwat and A. Buageaw, "Renal Functional Reserve in Lacto-Vegetarian Adolescents," Siriraj Medical Journal, Vol. 54, 2002, pp. 217-223.

[24] S. Barai, S. Gambhir, N. Prasad, R. K. Sharma, M. Ora, A. Kumar, A. Gupta, D. S. Parasar and B. Suneetha, "Levels of GFR and Protein-Induced Hyperfiltration in Kidney Donors: A Single Center Experience in India," American Journal of Kidney Diseases, Vol. 51, No. 3, 2008, pp. 407-414. doi:10.1053/j.ajkd.2007.11.008

[25] M. J. Wiseman, R. Hunt, A. Goodwin, J. L. Gross, H. Keen and G. C. Viberti, "Dietary Composition and Renal Function in Healthy Subjects," Nephron, Vol. 46, No. 1, 1987, pp. 37-42. doi: $10.1159 / 000184293$ 